OPEN ACCESS

Edited by:

Ying Ma,

University of Coimbra, Portugal

Reviewed by:

Vijai Kumar Gupta,

National University of Ireland Galway,

Ireland

Alexander A. Kamnev,

Institute of Biochemistry

and Physiology of Plants

and Microorganisms, Russian

Academy of Sciences, Russia

*Correspondence:

Giovanna Visioli,

Department of Life Sciences, University of Parma, Parco Area delle

Scienze 11/A, 43124 Parma, Italy

giovanna.visioli@unipr.it

Specialty section:

This article was submitted to

Plant Biotic Interactions,

a section of the journal

Frontiers in Plant Science

Received: 18 June 2015

Accepted: 31 July 2015

Published: 14 August 2015

Citation:

Visioli G, Vamerali T, Mattarozzi M,

Dramis $L$ and Sanangelantoni AM (2015) Combined endophytic

inoculants enhance nicke phytoextraction from serpentine soil in the hyperaccumulator Noccaea caerulescens.

Front. Plant Sci. 6:638. doi: 10.3389/fp/s.2015.00638

\section{Combined endophytic inoculants enhance nickel phytoextraction from serpentine soil in the hyperaccumulator Noccaea caerulescens}

\author{
Giovanna Visioli ${ }^{\star}$, Teofilo Vamerali ${ }^{2}$, Monica Mattarozzi ${ }^{3}$, Lucia Dramis ${ }^{1}$ and \\ Anna M. Sanangelantoni ${ }^{1}$ \\ 1 Department of Life Sciences, University of Parma, Parma, Italy, ${ }^{2}$ Department of Agronomy, Food, Natural Resources, \\ Animals and the Environment, University of Padova, Padova, Italy, ${ }^{3}$ Department of Chemistry, University of Parma, Parma, \\ Italy
}

This study assesses the effects of specific bacterial endophytes on the phytoextraction capacity of the Ni-hyperaccumulator Noccaea caerulescens, spontaneously growing in a serpentine soil environment. Five metal-tolerant endophytes had already been selected for their high $\mathrm{Ni}$ tolerance $(6 \mathrm{mM})$ and plant growth promoting ability. Here we demonstrate that individual bacterial inoculation is ineffective in enhancing $\mathrm{Ni}$ translocation and growth of $N$. caerulescens in serpentine soil, except for specific strains Ncr-1 and Ncr-8, belonging to the Arthrobacter and Microbacterium genera, which showed the highest indole acetic acid production and 1-aminocyclopropane1-carboxylic acid-deaminase activity. Ncr-1 and Ncr-8 co-inoculation was even more efficient in promoting plant growth, soil $\mathrm{Ni}$ removal, and translocation of $\mathrm{Ni}$, together with that of $\mathrm{Fe}, \mathrm{Co}$, and $\mathrm{Cu}$. Bacteria of both strains densely colonized the root surfaces and intercellular spaces of leaf epidermal tissue. These two bacterial strains also turned out to stimulate root length, shoot biomass, and Ni uptake in Arabidopsis thaliana grown in MS agar medium supplemented with $\mathrm{Ni}$. It is concluded that adaptation of $\mathrm{N}$. caerulescens in highly $\mathrm{Ni}$-contaminated serpentine soil can be enhanced by an integrated community of bacterial endophytes rather than by single strains; of the former, Arthrobacter and Microbacterium may be useful candidates for future phytoremediation trials in multiple metal-contaminated sites, with possible extension to non-hyperaccumulator plants. Keywords: plant growth-promoting endophytic bacteria (PGPE), serpentine soil, nickel, tissue colonization,
phytoextraction, Noccaea caerulescens, Arabidopsis thaliana

\section{Introduction}

Phytoextraction has been proposed as a low-cost effective technology for remediation of contaminated soils and for phytomining (Chaney et al., 2007). Phytoextraction implies the cultivation of plants which can accumulate trace metals from contaminated soils and transport them to the above-ground biomass, and then be harvested. Metal hyperaccumulator plants 
TABLE 1 | Enzymatic and hormonal activity (mean $\pm \mathrm{SD}, \boldsymbol{n}=3$ ) of bacterial strains isolated from roots of $\mathrm{Ni}$-hyperaccumulator $\mathrm{N}$. caerulescens in a previous work (Visioli et al., 2014).

\begin{tabular}{|c|c|c|c|c|c|c|c|c|}
\hline \multirow{2}{*}{$\begin{array}{l}\text { Bacterial } \\
\text { strain }\end{array}$} & \multirow{2}{*}{$\begin{array}{l}\text { Accession } \\
\text { number }\end{array}$} & \multirow{2}{*}{$\begin{array}{l}\text { Closest described } \\
\text { relative }\end{array}$} & \multicolumn{3}{|c|}{ Ni resistance } & \multirow{2}{*}{$\begin{array}{l}\text { Siderophore } \\
\text { production }\end{array}$} & \multirow{2}{*}{$\begin{array}{l}\text { IAA production } \\
\text { (mg L-1) }\end{array}$} & \multirow{2}{*}{$\begin{array}{l}\text { ACC deaminase activity } \\
\left(\mu \mathrm{M} \alpha \mathrm{KB} \mathrm{mg} \mathrm{mg}^{-1} \mathrm{~h}^{-1}\right)\end{array}$} \\
\hline & & & $1 \mathrm{mM}$ & $3 \mathrm{mM}$ & $6 \mathrm{mM}$ & & & \\
\hline Ncr-1 & KJ92857 & Arthrobacter sp. & +++ & +++ & +++ & + & $25.6 \pm 1.3$ & $20 \pm 2.5$ \\
\hline Ncr-3 & KJ92859 & Kocuria rhizophila & +++ & +++ & +++ & + & $14.5 \pm 2.8$ & ND \\
\hline Ncr-5 & KJ92861 & Bacillus sp. & +++ & +++ & +++ & + & $10.6 \pm 3.6$ & $11.01 \pm 2.0$ \\
\hline Ncr-8 & KJ92864 & Microbacterium oxydans & +++ & +++ & +++ & + & $20.8 \pm 2.4$ & $30 \pm 2.9$ \\
\hline Ncr-9 & KJ92865 & Bacillus amyloliquefaciens & +++ & +++ & +++ & + & $11.3 \pm 0.8$ & ND \\
\hline
\end{tabular}

ND, not detected; ACC, 1-aminocyclopropane-1-carboxylic acid; aKB, a-ketobutyrate; IAA, indole-3-acetic acid.

are ideal candidates for this technology, thanks to their extraordinary capacity for absorbing and accumulating metals in their shoots without showing symptoms of phytotoxicity (Baker et al., 2000). Unfortunately, most hyperaccumulators do not produce substantial quantities of biomass, thus hampering the management of phytoextraction. Understanding of the mechanisms underlying hyperaccumulation may allow this technology to be transferred to metal-tolerant and high biomassyielding plants (Ebbs and Kochian, 1998).

In recent years, attention has focused on microorganisms thriving in the rhizosphere or inhabiting the roots of hyperaccumulators which show plant growth-promoting activity (Sessitsch et al., 2013; Visioli et al., 2015). Plant growth-promoting rhizobacteria (PGPR) and endophytes [Plant growth-promoting endophytic bacteria (PGPE)] can also enhance plant tolerance, growth, and survival in stress conditions of metal-rich soils by reducing the nutrient deficiency and phytotoxicity of trace metals. This is achieved by the production of siderophores, carboxylic acids, and solubilisation of phosphates, which increase the mobility of macro- and micronutrients in the rhizosphere (Rajkumar et al., 2012; Bashan et al., 2013a,b). PGPR and PGPE can also promote growth, both indirectly by protecting plants against pathogens and directly by producing phytohormones such as indole acetic acid (IAA), abscisic acid, and gibberellic acid, and by secreting enzymes such as 1-aminocyclopropane-1-carboxylic acid (ACC) deaminase,

TABLE 2 | Physicochemical characteristics of serpentine soil used for growing inoculated and control $\boldsymbol{N}$. caerulescens plants.

\begin{tabular}{ll}
\hline Parameters & \\
\hline $\mathrm{pH}$ & $7.2-7.5$ \\
Organic matter (\%) & $2.95 \pm 0.21$ \\
Water content (\%) & $19.01 \pm 0.2$ \\
$\mathrm{Ca} / \mathrm{Mg}$ & $0.25 \pm 0.0$ \\
Total metal concentration $\mathbf{( m g ~ k g}^{-\mathbf{1}} \mathbf{)}$ & \\
$\mathrm{Fe}$ & $47120 \pm 341(62.5 \pm 3.4)$ \\
$\mathrm{Ni}$ & $1244 \pm 24(34.8 \pm 3.4)$ \\
$\mathrm{Zn}$ & $71 \pm 0.2(1.4 \pm 0.01)$ \\
$\mathrm{Co}$ & $97 \pm 1.3(7.3 \pm 0.03)$ \\
$\mathrm{Cu}$ & $11 \pm 0.1(2.3 \pm 0.01)$
\end{tabular}

Diethylene triamine pentaacetic acid (DTPA)-extractable fractions are reported in parenthesis. which inhibits ethylene production and consequently slows down plant aging. By lowering ethylene levels in plant tissues, ACC-deaminase reduces plant stress and improves growth under metal contamination, this being the main beneficial effect in phytoremediation (Kamnev, 2003; Spaepen et al., 2007; Belimov et al., 2009). The positive effects of PGPR and PGPE on plant growth and metal bioavailability can markedly improve metal accumulation by roots and shoots, thus efficiently influencing phytoremediation of metal-polluted sites (Li et al., 2007; Ma et al., 2009a,b, 2011a; Rajkumar et al., 2009, 2012; Chen et al., 2010; Sessitsch et al., 2013).

In many cases, the effects of plant-microbe interactions on growth and metal uptake has been shown to be species- and soil-specific (Sheng et al., 2008; Becerra-Castro et al., 2012; Cabello-Conejo et al., 2014), but interesting results have also been obtained by inoculating Ni-resistant PGPR isolated from the rhizosphere of Alyssum serpyllifolium and Astragalus incanus on the growth and Ni accumulation of Ricinus communis, Heliantus annus, and Brassica juncea, grown in single and multiple metalcontaminated soils (Ma et al., 2011a,b, 2015a; Jing et al., 2014). $\mathrm{Cd}$ - and $\mathrm{Pb}$-mobilizing rhizospheric bacteria also enhanced the uptake of metals in tomato plants (Jiang et al., 2008) and Znmobilizing bacteria, isolated from serpentine soils, promoted $\mathrm{Zn}, \mathrm{Cu}$, and $\mathrm{Ni}$ accumulation in $R$. communis (Rajkumar and Freitas, 2008). Recent studies have further confirmed the potential role of PGPE in metal accumulation. For instance, endophytes from the Bacillus genus isolated from the roots of the Zn/Cd hyperaccumulator Sedum plumbizincicola, can effectively enhance plant biomass and Cd or Zn uptake (Ma et al., 2015b). A Cd-mobilizing endophytic strain isolated from maize roots can also improve Cd uptake by hyperaccumulator plants of the genus Amaranthus (Yuan et al., 2014); Rahnella sp. JN6, isolated from Polygonum pubescens, can also promote growth and $\mathrm{Cd}$, $\mathrm{Pb}$, and $\mathrm{Zn}$ uptake in the biomass species B. napus (He et al., 2013).

The increasing number of bacterial strains with beneficial effects on plant growth and metal accumulation traits, isolated from contaminated soil environments, both in the rhizosphere and from the roots of hyperaccumulator plant species, may contribute to the creation of a "bacteria phytoremediation database," to be used to check the effectiveness of bacterial inocula on various high-yielding biomass plant species, for possible future applications in the phytomanagement of polluted sites. 

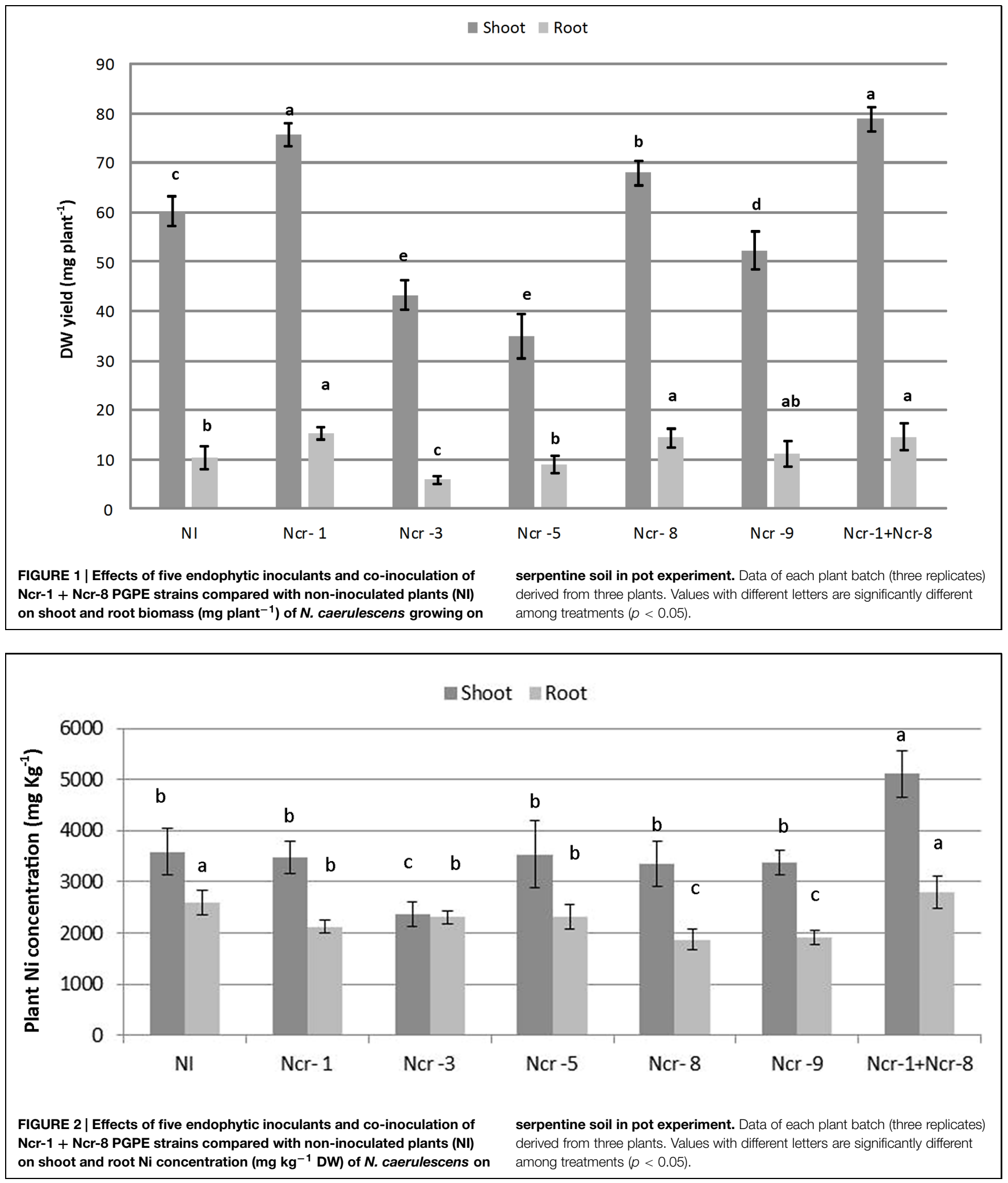

Within this framework, we studied the interaction between the Ni-hyperaccumulator Noccaea caerulescens and five PGPE, previously isolated from its roots in a serpentine soil. Bacteria were supplied as the seed inoculum of each strain, both separately and in combination, in order to identify any synergistic mechanism. Characterisation of IAA production and ACC- 
TABLE 3 | Nickel translocation factor (TF), calculated as shoot-to-root Ni concentration ratio and bioconcentration factor (BCF), determined as ratio of shoot $\mathrm{Ni}$ and total soil $\mathrm{Ni}$ concentrations (mean $\pm \mathrm{SD}, n=3$ ) in $\mathrm{N}$. caerulescens inoculated with five bacterial strains.

\begin{tabular}{|c|c|c|c|c|c|c|c|}
\hline & NI & Ncr-1 & Ncr-3 & Ncr-5 & Ncr-8 & Ncr-9 & Ncr-1 + Ncr-8 \\
\hline $\mathrm{TF}$ & 1.4 & 1.6 & 1.0 & 1.5 & 1.8 & 1.8 & 1.8 \\
\hline $\mathrm{BCF}$ & $2.9 \pm 0.1$ & $2.7 \pm 0.5$ & $1.9 \pm 0.2$ & $2.8 \pm 0.3$ & $2.7 \pm 0.2$ & $2.7 \pm 0.4$ & $4.0 \pm 0.5^{*}$ \\
\hline
\end{tabular}

* Significant differences $(p<0.05)$ between non-inoculated (NI) and treated plants.

deaminase activity in these bacteria also showed which of these physiological traits are efficient selection criteria for improving assisted metal phytoextraction. In this study, we documented plant-bacteria interactions by in vivo and in vitro microscopic observations, and attempted to transfer the technology in vitro to the non-hyperaccumulator Arabidopsis thaliana with the most efficient bacterial isolates.

\section{Materials and Methods}

\section{Bacterial Strains}

The endophytic bacteria tested here, Ncr-1, Ncr-3, Ncr-5, Ncr8 , and Ncr-9, had been isolated in a previous study from inners of the roots of $N$. caerulescens plants collected in serpentine soil in the Northern Italian Apennines (Visioli et al., 2014). They were selected from ten different strains on the basis of their greater ability to tolerate high concentrations of $\mathrm{Ni}$ in hydroponics $(6 \mathrm{mM})$ and to produce plant growth-promoting substances (Table 1).

\section{Bacterial Seed Inoculation and Plant Germination In Vitro}

Ncr-1, Ncr-3, Ncr-5, Ncr-8, and Ncr-9 strains were grown overnight in $100 \mathrm{~mL}$ Luria Bertani (LB) medium at $30^{\circ} \mathrm{C}$ on a rotary shaker. Cells were collected by centrifugation and suspended in LB medium to obtain a final inoculum density of $10^{8} \mathrm{CFU} \mathrm{mL} \mathrm{m}^{-1}$. N. caerulescens seeds were surface sterilized in $50 \%(\mathrm{v} / \mathrm{v})$ commercial bleach (5\% sodium hypochlorite and $0.05 \%$ sodium hydroxide) in water for $15 \mathrm{~min}$ and then rinsed for $5 \mathrm{~min}$ in sterile water three times. Seeds were kept for $2 \mathrm{~h}$ in a bacterial suspension of $5 \times 10^{8}$ cells $\mathrm{mL}^{-1}$ of each strain or in

TABLE 4 | Diethylene triamine pentaacetic acid- extractable fractions of metals (mean $\pm \mathrm{SD}, n=3$ ) in rhizosphere soil of inoculated and control $N$. caerulescens plants at harvest (end of experiment).

\begin{tabular}{|c|c|c|c|c|}
\hline & $\begin{array}{l}\mathrm{Ni} \\
\mathrm{mg} \mathrm{kg}^{-1}\end{array}$ & $\begin{array}{l}\mathrm{Zn} \\
\mathrm{mg} \mathrm{kg}^{-1}\end{array}$ & $\begin{array}{l}\text { Co } \\
\mathrm{mg} \mathrm{kg}^{-1}\end{array}$ & $\begin{array}{l}\mathrm{Cu} \\
\mathrm{mg} \mathrm{kg}^{-1}\end{array}$ \\
\hline $\mathrm{NI}$ & $34.8 \pm 3.4$ & $1.4 \pm 0.01$ & $7.3 \pm 0.03$ & $2.3 \pm 0.01$ \\
\hline Ncr-1 & $35.4 \pm 2.5$ & $1.4 \pm 0.03$ & $7.4 \pm 0.02$ & $2.3 \pm 0.02$ \\
\hline Ncr-3 & $34.8 \pm 1.3$ & $1.5 \pm 0.05$ & $7.3 \pm 0.04$ & $2.4 \pm 0.03$ \\
\hline Ncr-5 & $34.3 \pm 1.2$ & $1.7 \pm 0.06$ & $7.3 \pm 0.05$ & $2.3 \pm 0.07$ \\
\hline Ncr-8 & $36.5 \pm 2.9^{*}$ & $1.4 \pm 0.10$ & $7.1 \pm 0.10$ & $2.4 \pm 0.02$ \\
\hline Ncr-9 & $35.8 \pm 2.5$ & $1.5 \pm 0.05$ & $7.1 \pm 0.02$ & $2.2 \pm 0.01$ \\
\hline $\mathrm{Ncr} 1+\mathrm{Ncr} 8$ & $36.2 \pm 1.3^{*}$ & $1.5 \pm 0.04$ & $7.0 \pm 0.01$ & $2.3 \pm 0.01$ \\
\hline
\end{tabular}

* Significant difference $(p<0.05$ ) between inoculated plants and non-inoculated (NI) controls.

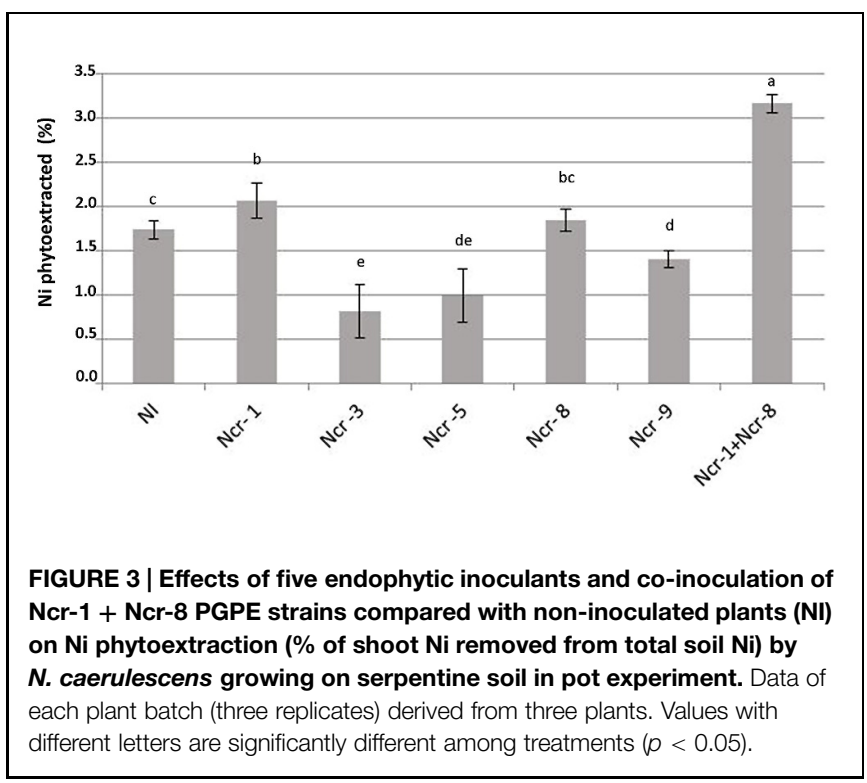

a bacterial suspension of both Ncr-1 and Ncr-8 strains $\left(5 \times 10^{8}\right.$ cells $\mathrm{mL}^{-1}$ of each) and then thoroughly washed in sterilized water. The seeds were then plated on $1 \times$ MS (Murashige and Skoog, 1962) agar medium and incubated in a vertical position in an environmentally controlled room $\left(22^{\circ} \mathrm{C} ; 16 \mathrm{~h} / 8 \mathrm{~h}\right.$ light/dark; $\left.120 \mu \mathrm{mol} \mathrm{m}{ }^{-2} \mathrm{~s}^{-1} \mathrm{PAR}, 75 \% \mathrm{RH}\right)$ to determine germination and root elongation. The same sterilization and co-inoculation procedures were used for $A$. thaliana seeds with Ncr-1 and Ncr-8 strains.

\section{Soil Experiments}

The soil used in these experiments was collected at a previously characterized site on Mount Prinzera, a serpentine outcrop in the Northern Italian Apennines (GPS $44.64282^{\circ} \mathrm{N}-10.07951^{\circ} \mathrm{E}$; for basic soil properties, see Visioli et al., 2013, and Table 2).

Soil $\mathrm{pH}$ was measured with a glass electrode from a deionised water suspension (20 g soil/50 mL water) after $1 \mathrm{~h}$ agitation and overnight settlement. Organic matter was determined on soils sampled at depths of 10 and $20 \mathrm{~cm}$ as LOI (weight loss on ignition; Storer, 1984). Aliquots of $2 \mathrm{~g}$ of each sample were placed in closed ceramic crucibles for $3 \mathrm{~h}$ at $450^{\circ} \mathrm{C}$; organic matter was calculated as the fraction of weight decrease. Soil water content was measured on 20-g samples, placed in closed heat-resistant plastic containers, previously weighed and placed in an oven at $70^{\circ} \mathrm{C}$ for $24 \mathrm{~h}$. The percentage of water in the sediment was calculated as weight loss from the initial weight. The soil was then sieved $(2 \mathrm{~mm})$ and sterilized at $80^{\circ} \mathrm{C}$ for $24 \mathrm{~h}$. 


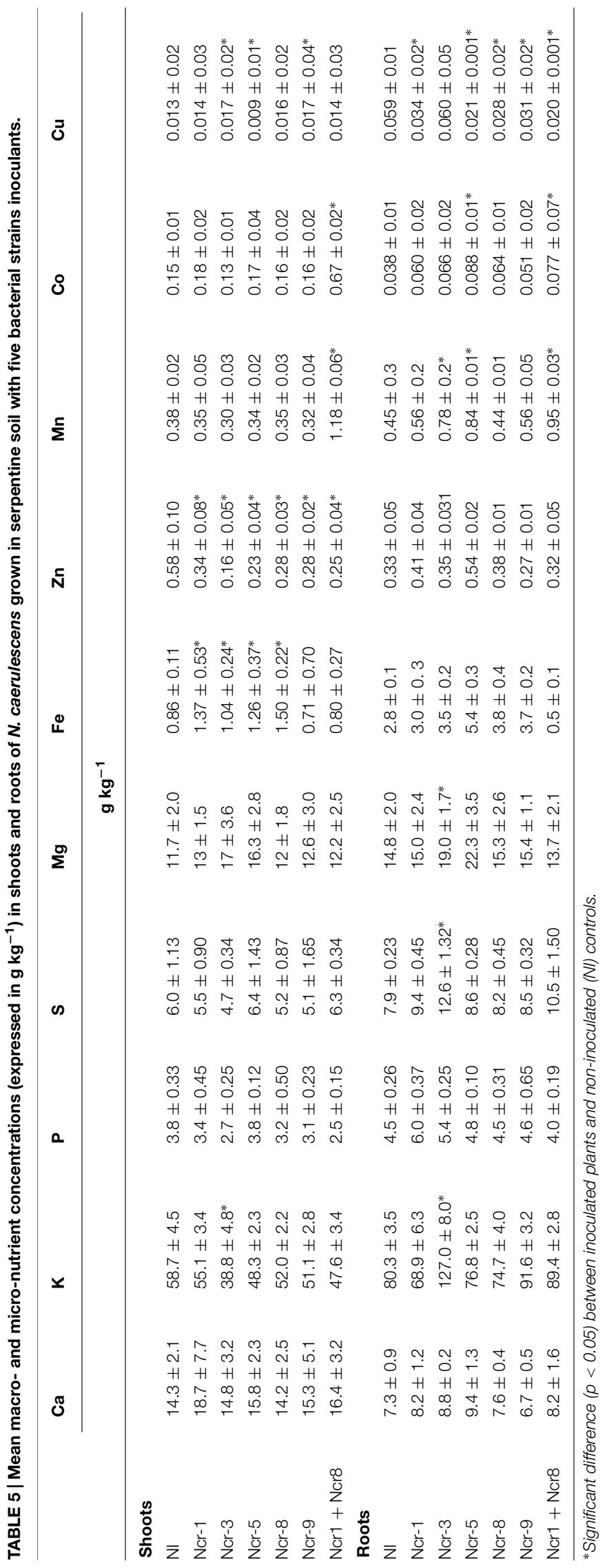

Fourteen-day-old N. caerulescens seedlings (three per pot), inoculated and non-inoculated with the various bacterial strains, were transferred into PVC pots (upper diameter $110 \mathrm{~mm}$, lower diameter $90 \mathrm{~mm}$, height $100 \mathrm{~mm}$ ) containing $750 \mathrm{~g}$ of soil, with three replicates. The plants were grown in the same conditions as above and the soil was wetted with sterile water and maintained at $25 \% \mathrm{w} / \mathrm{w}$ of water content (corresponding to $50 \%$ of its holding capacity). The experiment was set up in September 2014 and lasted 60 days, after which the plants were carefully lifted from the pots and the soil was removed from their roots. Plant roots were immersed in a $10 \mathrm{mM}$ EDTA solution for $30 \mathrm{~min}$ and rinsed thoroughly with deionised water to avoid any metal contamination. Shoots and roots were then dried for 3 days at $70^{\circ} \mathrm{C}$ and root and shoot dry weights (DW) were recorded.

Hundred-mg samples of dried shoots or roots were microwave-acid digested (Milestone ETHOS 900, Bergamo, Italy) by the addition of $7 \mathrm{~mL}$ ultrapure grade $6 \mathrm{HNO}_{3}(65 \% \mathrm{v} / \mathrm{v})$ and $1 \mathrm{~mL}$ suprapur $\mathrm{H}_{2} \mathrm{O}_{2}(30 \% \mathrm{v} / \mathrm{v})$, according to the EPA 3052 method (USEPA, 1995). The microwave setting reached $200^{\circ} \mathrm{C}$ in $10 \mathrm{~min}$ (step 1), followed by $10 \mathrm{~min}$ at $200^{\circ} \mathrm{C}$ (step 2), and a final air cooling phase down to $<30^{\circ} \mathrm{C}$. In steps 1 and 2 , maximum pressure and power were 45 bar and $1.2 \mathrm{~kW}$, respectively. Samples were then diluted to $25 \mathrm{~mL}$ with distilled water, filtered (0.45 $\mu \mathrm{m}$ PTFE) and analyzed by ICP-OES (SPECTRO Ciros Vision EOP, Spectro Analytical Instruments, Kleve, Germany) to reveal metal concentrations. Certified reference materials (ERM-CD281 and BRC-402, JRC-IRMM, Belgium) were used to ensure measurement accuracy. Data are expressed in $\mathrm{mg}$ $\mathrm{kg}^{-1} \mathrm{DW}$ plant material. The Ni translocation factor (TF) was measured as the shoot-to-root metal concentration ratio.

Aliquots of $300 \mathrm{mg}$ of soil collected in the rhizosphere of both inoculated and non-inoculated plants were also dried overnight at $70^{\circ} \mathrm{C}$ and wet-ashed; total $\mathrm{Ni}$ concentration was determined by ICP-OES, with the same procedure as above.

In addition, in order to evaluate $\mathrm{Ni}, \mathrm{Zn}, \mathrm{Cu}$, and $\mathrm{Co}$ bioavailability, the same samples underwent diethylene triamine pentaacetic acid (DTPA) extraction. Bioavailable metals were extracted on $50 \mathrm{~g}$ of homogenized air-dried soil through a $100-\mathrm{mL}$ solution of DTPA (1.97 $\left.\mathrm{g} \mathrm{L}^{-1}\right)$, calcium chloride bihydrate $\left(1.46 \mathrm{~g} \mathrm{~L}^{-1}\right)$, and triethanolamine (14.92 $\mathrm{g}$ $\left.\mathrm{L}^{-1}\right)$, $\mathrm{pH} 7.3$, shaken for $2 \mathrm{~h}\left(60\right.$ cycles $\left.\min ^{-1}\right)$. Samples were analyzed by ICP-OES after centrifugation (5 $\mathrm{min}$, $2599 \times g)$.

The ability of Ncr-1, Ncr-3, Ncr-5, Ncr-8, and Ncr9 to bioconcentrate $\mathrm{Ni}$ in the above-ground biomass of $N$. caerulescens from serpentine soil (BCF: Bioconcentration factor) was calculated as the ratio between shoot $\mathrm{Ni}$ concentration and soil pseudo-total $\mathrm{Ni}$ concentration. The effect of microbial inoculation on overall $\mathrm{Ni}$ phytoextraction efficiency was assessed by taking into account plant growth, and was calculated as the product of DW shoot yield and its $\mathrm{Ni}$ concentration.

After log-transformation of the response variables, ANOVA and Tukey's post hoc test were used to ascertain differences in root length, root and shoot biomass and metal concentrations. 
TABLE 6 | Shoot-to-root concentration ratio (TF) of main macro- and micro-nutrients (mean \pm SD, $n=3$ ) in $N$. caerulescens grown in serpentine soil with five bacterial strain inoculants.

\begin{tabular}{|c|c|c|c|c|c|c|c|c|c|c|}
\hline & $\mathbf{C a}$ & $\mathbf{K}$ & $\mathbf{P}$ & $\mathbf{S}$ & $\mathbf{M g}$ & $\mathrm{Fe}$ & $\mathrm{Zn}$ & Mn & Co & $\mathrm{Cu}$ \\
\hline \multicolumn{11}{|c|}{ TF } \\
\hline $\mathrm{NI}$ & 2.0 & 0.7 & 0.8 & 0.8 & 0.8 & 0.3 & 1.8 & 0.8 & 3.9 & 0.2 \\
\hline Ncr-1 & 2.3 & 0.8 & 0.6 & 0.6 & 0.9 & 0.4 & $0.8^{*}$ & 0.6 & 3.0 & 0.4 \\
\hline Ncr-3 & 1.7 & 0.3 & 0.5 & 0.4 & 0.9 & 0.3 & $0.5^{*}$ & 0.4 & 2.0 & 0.2 \\
\hline Ncr-5 & 1.7 & 0.6 & 0.8 & 0.7 & 0.7 & 0.2 & $0.4^{*}$ & 0.4 & 1.9 & 0.4 \\
\hline Ncr-8 & 1.9 & 0.7 & 0.6 & 0.6 & 0.8 & 0.4 & $0.7^{*}$ & 0.8 & 2.5 & 0.6 \\
\hline Ncr-9 & 2.3 & 0.6 & 0.7 & 0.6 & 0.8 & 0.2 & 1.1 & 0.6 & 3.1 & 0.6 \\
\hline Ncr1 + Ncr8 & 2.0 & 0.5 & 0.6 & 0.6 & 0.9 & $1.6^{*}$ & $0.8^{*}$ & $1.2^{*}$ & $8.7^{*}$ & $0.7^{*}$ \\
\hline
\end{tabular}

* Significant difference $(p<0.05)$ between inoculated plants and non-inoculated (NI) controls.

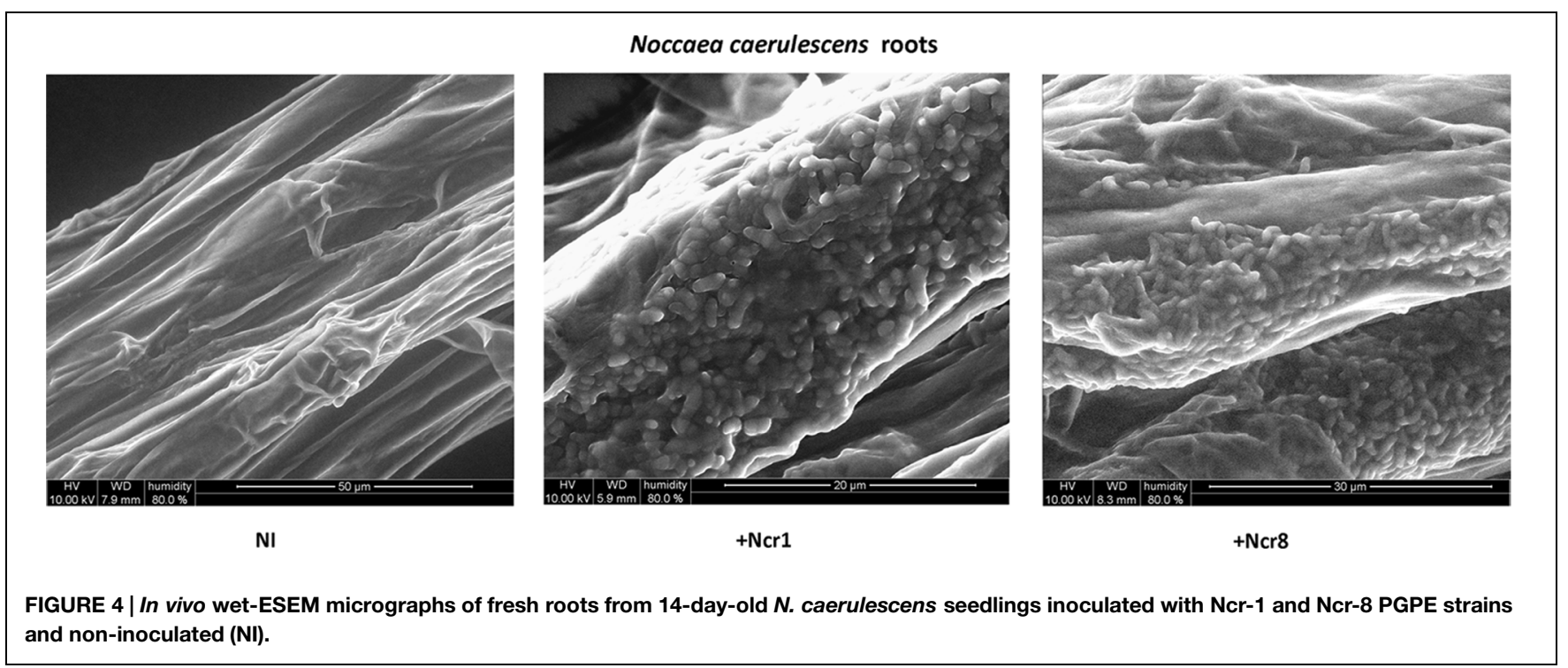

\section{Electron Microscopy Analysis}

Fresh roots from 14-day-old $N$. caerulescens seedlings inoculated with Ncr-1 and Ncr-8 were directly collected from the plates and rinsed briefly in sterile water; $5-\mathrm{mm}$ root sections were then excised with a sterile lancet. Unfixed and hydrated samples were directly analyzed under an Environmental Scanning Electron Microscope (ESEM) Quanta $^{\text {TM }} 250$ FEG (FEI, Hillsboro, OR, USA), operating in wet mode conditions. In more detail, samples were placed on double-sided adhesive carbon tape fixed to a precooled metal sample holder, in thermal contact with a Peltier cooling stage maintained at $3^{\circ} \mathrm{C}$. Accelerating voltage was $10 \mathrm{kV}$ and the secondary electron signal was collected by a gaseous secondary electron detector (GSED) to generate micrographs for morphological studies. Relative humidity was initially set at $100 \%$, and then slowly decreased to $80 \%$ by adjusting chamber pressure.

\section{Optical Microscopy Analysis}

Five-mm root and leaf sections were excised with a sterile lancet from in vitro 14-day-old N. caerulescens seedlings, inoculated and non-inoculated with Ncr-1 and Ncr-8 strains, collected from Petri dishes, and immediately fixed overnight at $4^{\circ} \mathrm{C}$ in formalin-acetic acid-alcohol (FAA). After this step, samples were dehydrated in a tertiary butyl-alcohol series and gradually embedded in paraffin. They were then cut into sections $5 \mu \mathrm{m}$ thick with a rotary microtome (Reichert-Jung 2040) and stained with safranin-fast green (Berlyn and Miksche, 1976). Lastly, they were analyzed under a Nikon eclipse E600 microscope mounted with a DS-FIZ camera.

\section{Results and Discussion}

\section{Plant Biomass Yield}

Solving the problem of interactions between $N$. caerulescens and PGPE in serpentine soil, which is characterized by low levels of essential nutrients and elevated $\mathrm{Ni}$, together with other toxic metals, can be illuminating in understanding plantmicroorganism interactions in an extremely adverse environment and the potential use of metal-resistant endophytic bacteria in phytomanagement of metal-polluted sites.

In a previous work, five culturable bacterial endophytes were selected among 10 isolates from $N$. caerulescens roots according to their high resistance to $\mathrm{Ni}$ and ability to produce PGP 


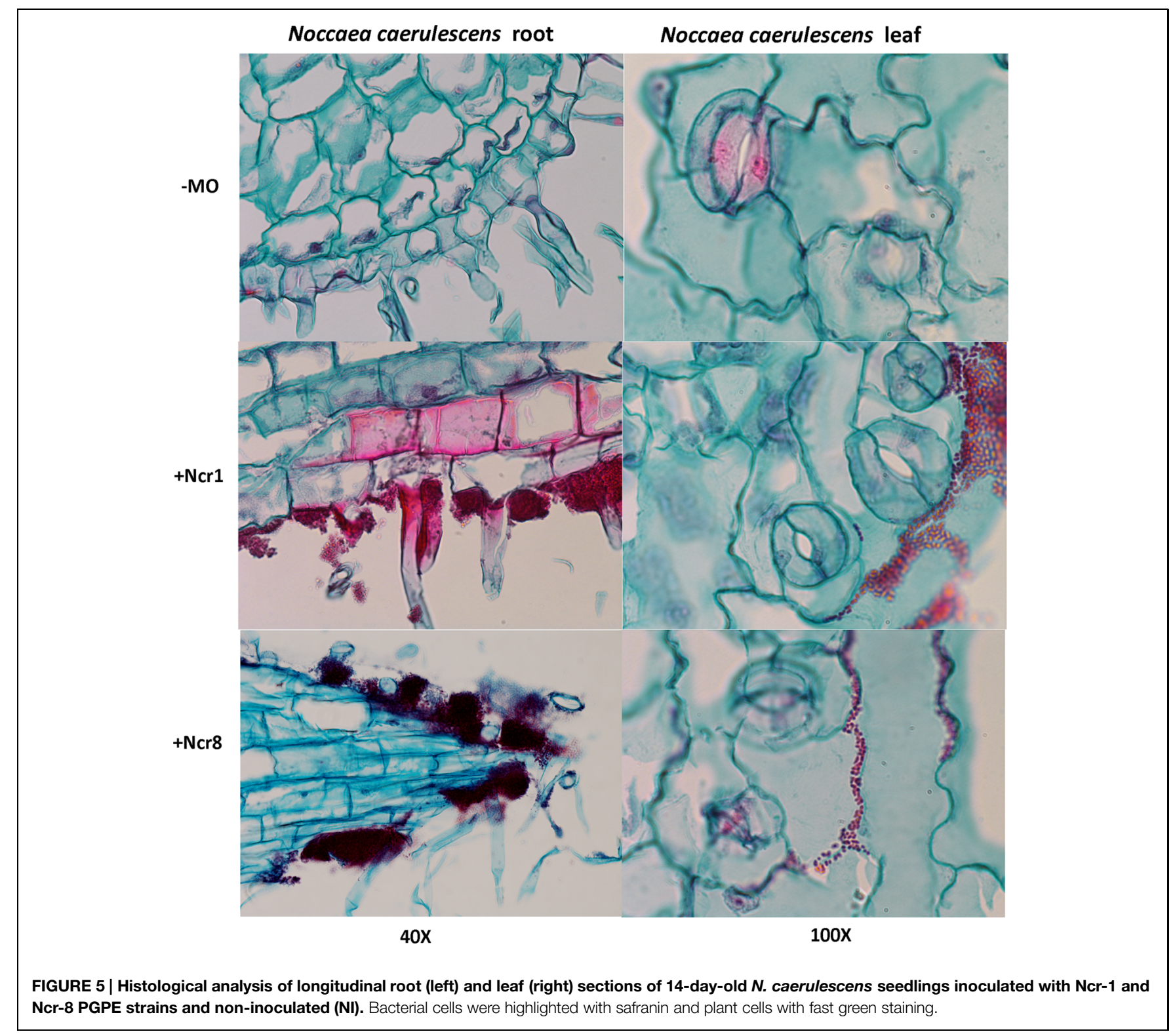

metabolites such as IAA, ACC-deaminase, and siderophores (Table 1).

These five inoculants promoted plant growth and $\mathrm{Ni}$ translocation in a hydroponic system, enriched with $10 \mu \mathrm{M}$ $\mathrm{Ni}$ and supplied adequately with nutrients for growth (Visioli et al., 2014). Since in the real environment soil properties can greatly affect shoot growth and bacterial root colonization, essential nutrients often being limiting factors, in the present study the performance of these bacteria were further investigated in conditions more similar to those of open fields. The serpentine soil used was the original soil from which the Ni-hyperaccumulator $N$. caerulescens was first collected. The soil has a relatively low content of organic matter $(<3 \%)$ and neutral $\mathrm{pH}$ (Table 2). In addition, it has a low $\mathrm{Ca} / \mathrm{Mg}$ ratio, responsible for $\mathrm{Ca}$ uptake inhibition, and high levels of $\mathrm{Mg}$ (>300 $\mathrm{mg} \mathrm{kg}^{-1}$; Visioli et al., 2013) and several toxic metals, particularly $\mathrm{Ni}\left(>1000 \mathrm{mg} \mathrm{kg}^{-1}\right)$. Low levels of available macronutrients $\mathrm{N}, \mathrm{K}, \mathrm{P}$ were further edaphic constraints which severely affect plant growth and reproduction.

Noccaea caerulescens seeds were either inoculated with the five bacterial strains separately, or co-inoculated with strains Ncr-1 and Ncr- 8 together, in order to determine the potential additive effects of PGPE on plant growth and $\mathrm{Ni}$ accumulation in serpentine soil. Both $\mathrm{Ncr}-1$ and $\mathrm{Ncr}-8$ showed the highest IAA production and AAC-deaminase activity (Table 1). Among treatments with single inoculants, only plants treated with Ncr1 and Ncr-8 showed significant higher shoot biomass compared with untreated controls, i.e., +25 and $+12 \%$, respectively (Figure 1). Co-inoculum with Ncr-1 and Ncr-8 had a synergistic effect, with a further shoot DW increase of 4 and $16 \%$ with respect to Ncr-1 and Ncr-8 alone, respectively. Plant inoculation 

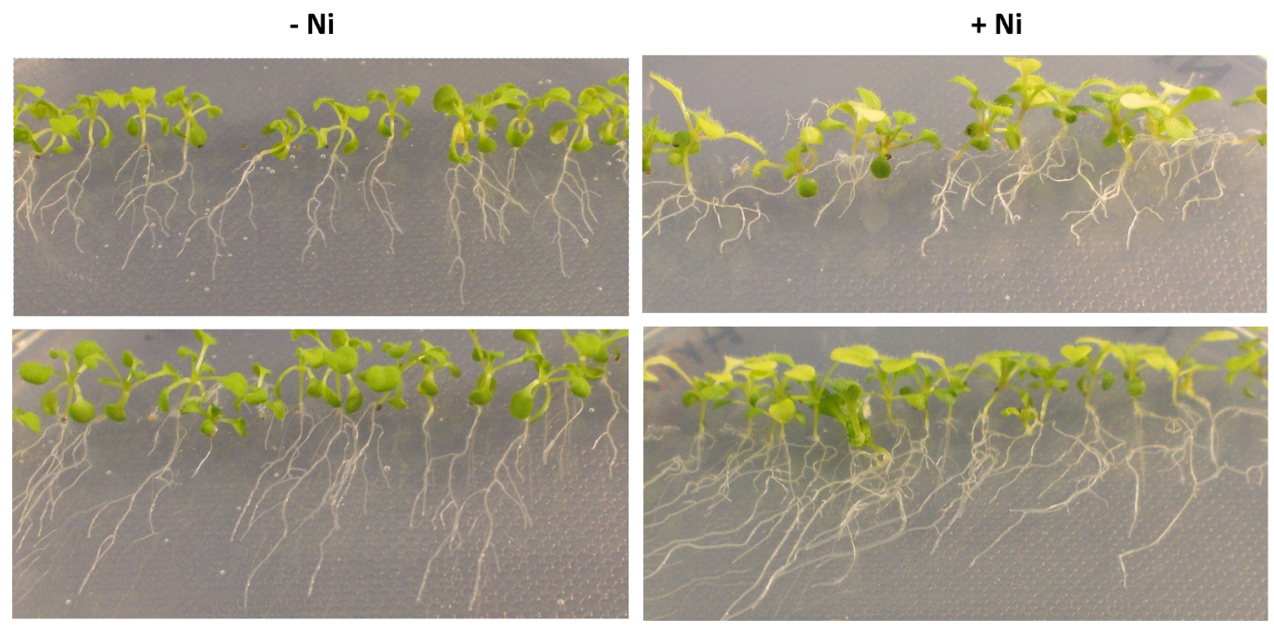

A. thaliana

A. thaliana Ncr-1+Ncr-8

FIGURE 6 | Seven-day-old Arabidopsis thaliana seedlings, non-inoculated (NI) or co-inoculated with Ncr-1 and Ncr-8 PGPE strains growing in MS 1x medium, with or without $40 \mu \mathrm{M} \mathrm{NiSO}_{4}$.

with Ncr-3, Ncr-5, and Ncr-9 produced a significant decrease in shoot and seldom (Ncr-3) in root biomasses, compared with non-inoculated controls, suggesting their poor interaction with N. caerulescens (Figure 1). The beneficial effects of bacterial inoculants on the growth of metal-exposed plants have often been attributed to the production and transfer to plants of high IAA levels (Spaepen et al., 2007; Dell'Amico et al., 2008). The positive influence of the Ncr-1 + Ncr8 combination on the biomass yield may be due to their substantial release of auxin, associated with reduced ethylene production through increased ACC-deaminase activity. IAA increases plant growth by promoting cell division or stimulating cell elongation (Spaepen et al., 2007), whereas ACC-deaminase effectively reduces ethylene production by plants, retarding leaf senescence (Glick et al., 1998) and increasing plant yield (Belimov et al., 2009).

The data presented here are consistent with recent results from the literature, evidencing the positive effect on growth of the Ni-hyperaccumulator Alyssum pintodasilvae of PGPR and PGPE strains belonging to Arthrobacter and Microbacterium genera in a serpentine soil (Cabello-Conejo et al., 2014). The beneficial role of PGPE belonging to the Bacillus genus on the growth of the $\mathrm{Cd} / \mathrm{Zn}$ hyperaccumulator S. plumbizincicola grown in a multiple-metal contaminated soil has also recently been demonstrated (Ma et al., 2015b).

Among bacterial inoculants, plant growth impairment was particularly evident with strain Ncr-3, since both shoot and root biomass were reduced by 28 and 39\%, respectively, compared with non-inoculated plants. Ncr-3 showed great similarity to Kocuria rhizophila, and its negative effect on $N$. caerulescens is in contrast with results in recent literature, which reports a positive influence on growth and chromium accumulation in Cicer arietinum L, although with a different $K$. flava species isolated from the rhizosphere of chickpea (Singh et al., 2014). Our Kocuria strain, coming from the rhizosphere of $N$. caerulescens, was found to have poor IAA production, and lacked ACC-deaminase activity, probably indicating the importance of this hormone and enzymatic activities in establishing positive interactions with plants.

\section{Ni Uptake and Translocation, and Shoot and Root lonome}

The Ni rate in roots of Ncr-1 + Ncr-8 co-inoculated plants and untreated controls was very similar $\left(2.6 \pm 0.4 \mathrm{~g} \mathrm{~kg}^{-1}\right.$ vs. $\left.2.7 \pm 0.4 \mathrm{~g} \mathrm{~kg}^{-1}\right)$, although significantly lower values $(p<0.05)$ were observed in all other treatments with single strains. Analysis of shoot tissues confirmed that $\mathrm{Ni}$ was significantly higher in the co-inoculated $\mathrm{NCr}-1+\mathrm{NCr}-8$ plants compared with untreated controls $\left(5.1 \pm 0.3 \mathrm{~g} \mathrm{~kg}^{-1}\right.$ vs. $\left.3.5 \pm 0.2 \mathrm{~g} \mathrm{~kg}^{-1}\right)$, and the absence of significant differences among control plants and single-strain inoculated plants, with the exception of Ncr3 , which showed reduced rates $\left(2.3 \pm 0.1 \mathrm{~g} \mathrm{~kg}^{-1}\right.$; Figure 2). Anyway, shoot Ni rates in N. caerulescens were extremely high with all bacteria strains, according with the capability of this $\mathrm{Ni}$ hyperaccumulator species. The shoot-to-root $\mathrm{Ni}$ ratio was $>1$ in all treatments except for $\mathrm{Ncr}-3(\mathrm{TF}=1.0$; Table 3) and was improved with strains Ncr-1 and Ncr-8 and their co-inoculation, confirming the general ability of $N$. caerulescens to accumulate $\mathrm{Ni}$ above-ground and involvement of these bacteria in Ni uptake and translocation (Table 3 ).

Nevertheless, Ni soil bioavailability was similar before and after plant growth and did not apparently change in the rhizosphere as a consequence of bacteria inoculation, with an average value of $35.4 \mathrm{mg} \mathrm{kg}^{-1}$ as DTPA extractable fraction at end of the experiment (Table 4). Compared with non-inoculated controls, inoculants led to some small changes only in $\mathrm{Ni}$ phytoavailability, with an increase with Ncr-8 and Ncr1 + Ncr8 co-inoculation. The same effect was observed for $\mathrm{Zn}, \mathrm{Co}$, and $\mathrm{Cu}$, with no variations following inoculation.

In the literature, contrasting results are described as regards the effects of rhizosphere bacteria on soil metal mobility. 
For instance, Microbacterium arabinogalactolyticum was found to increase the soil extractability of $\mathrm{Ni}$ (Abou-Shanab et al., 2003, 2006), although no variations were observed with Arthrobacter nitroguajacolicus and Microbacterium sp. inoculants in serpentine soil with the Ni-hyperaccumulator A. pintodasilvae (Cabello-Conejo et al., 2014). The dynamic nature of metal solution-solid phase interactions would explain the absence of a direct correlation between Ni uptake and its DTPA extractable fraction.

Co-inoculation of Ncr-1 and Ncr-8 strains appreciably improved the BCF, i.e., 1.38 times higher than that of untreated controls $(P<0.05$; Table 3$)$. As a consequence, the percentage of Ni removal was significantly higher than in non-inoculated plants (3.2\% vs $1.7 \%)$; in single-strain inoculated plants, only Ncr-1 showed significantly higher $\mathrm{Ni}$ phytoextraction $(2.1 \%$; Figure 3). Ncr-8 led to the same phytoextraction capacity as controls, whereas Ncr-3, Ncr-5, and Ncr-9 had significantly lower capacities. These results indicate that, with the combined help of two selected bacteria, $N$. caerulescens can take up Ni from the soil more efficiently than in aseptic conditions, confirming previous findings on the stimulation effects of endophytes on metal uptake in higher plants (He et al., 2013; Yuan et al., 2014; Ma et al., 2015b).

As regards other elements, both shoot and root tissues had similar concentrations of the main macronutrients $\mathrm{Ca}, \mathrm{K}, \mathrm{Mg}$, $\mathrm{P}$, and $\mathrm{S}$ between inoculated and untreated plants. The only exception was $\mathrm{Ncr}$-3, which showed a significant decrease in shoot $\mathrm{K}$, together with root $\mathrm{K}, \mathrm{S}$, and $\mathrm{Mg}$ increases (Table 5). Some trace metals also seldom changed between treatments; bacterial inoculation generally led to a substantial $\mathrm{Zn}$ decrease in shoots, regardless of bacterial strain, and a generalized $\mathrm{Cu}$ decrease in roots, except for Ncr-3 (Table 5). The response of Co was peculiar, in that distribution in both shoot and roots only increased with Ncr-1 + Ncr-8 co-inoculation.

As a consequence of such variations in plant metal rates, a general decrease in the shoot-to-root concentration ratio for $\mathrm{Zn}$ (i.e., TF) was observed in inoculated plants, whereas only co-inoculation with Ncr-1 and Ncr-8 significantly increased the $\mathrm{TF}$ of $\mathrm{Fe}, \mathrm{Co}$, and $\mathrm{Cu}$ compared with untreated controls and single inoculants (Table 6). According to some recent studies, siderophore production and $\mathrm{P}$ solubilisation by rhizosphere microrganisms play important roles in increasing the mobility of several trace metals in polluted substrates, thus facilitating their accumulation in plant tissues (Sessitsch et al., 2013). In our case, both Ncr-1 and Ncr-8 had good siderophore production, but real improvements in $\mathrm{Ni}, \mathrm{Mn}$, and $\mathrm{Co}$ accumulation in the above-ground biomass of $N$. caerulescens were observed when the ability of the two efficient strains were combined. As suggested by Rajkumar et al. (2012), siderophores can chelate the unavailable ferric form of iron in near-neutral $\mathrm{pH}$ conditions, allowing more efficient uptake of this metal by $N$. caerulescens roots, and we recorded a slight increase in shoot and root $\mathrm{Fe}$ accumulation with some bacterial strains. Instead, the general reduction in shoot $\mathrm{Zn}$ of all inoculated treatments was probably due to the mobilization of various metals present at higher concentrations in serpentine soils. These soils are commonly poor in $\mathrm{Zn}\left(\sim 70 \mathrm{mg} \mathrm{kg}^{-1} \mathrm{DW}\right.$ in our case $)$ and competition with other abundant metals such as $\mathrm{Ni}\left(>1000 \mathrm{mg} \mathrm{kg}^{-1}\right.$ soil DW), Co (>90 $\mathrm{mg} \mathrm{kg}^{-1}$ soil DW) and Cu may explain the lower uptake and translocation of $\mathrm{Zn}$. This hypothesis was apparently not supported by the stable DTPA-extractable fraction of the most abundant trace metals, but quantification of metal mobility at harvest is a final result which may not have described specific variations during the developmental stages of plants.

\section{Physical Interaction between Plants and Bacteria}

An important aspect to consider in root-microbe interactions is the possibility of tracking bacterial growth and plant tissue colonization (Visioli et al., 2015). Some authors have recently followed bacterial colonization after a certain time from inoculation by means of classic microbiological methods, with selection of metal-resistant bacteria. The bacteria are then identified by colony morphology traits, metal-contamination tolerance, and IAA production and ACC-deaminase activity (Ma et al., 2015b). Until now, very few studies have shown physical plant-microbe interactions in the tissues of hyperaccumulator plants. We monitored the colonization and survival of inocula in real environmental conditions by environmental scanning electron in vivo microscopy (ESEM). ESEM is a powerful tool which allows observation of biological specimens in situ without sample preparation (Stabentheiner et al., 2010). The physical association between the roots of $N$. caerulescens and Ncr-1 and Ncr-8 was analyzed on 14-day-old seedlings from inoculated seeds before the soil experiments were set up. Single Ncr-1 and Ncr-8 strains showed deep colonization in root cavities and deep bacterial root biofilm formation (Figure 4). Images obtained after histological staining of 14-day-old $N$. carulescens seedlings inoculated with single Ncr-1 and Ncr- 8 bacteria, compared with non-inoculated plants, are shown in Figure 5. Both strains adhered closely to the root epidermis and root tips. They were also very abundant on leaf tissues, penetrating the intercellular

TABLE 7 | Root length, fresh plant weight, and Ni content ( \pm SE, $n=3$ ) in 7-day-old Arabidopsis thaliana seedlings grown in vitro under 0 or $40 \mu M$ $\mathrm{NiSO}_{4}$, with or without inoculation.

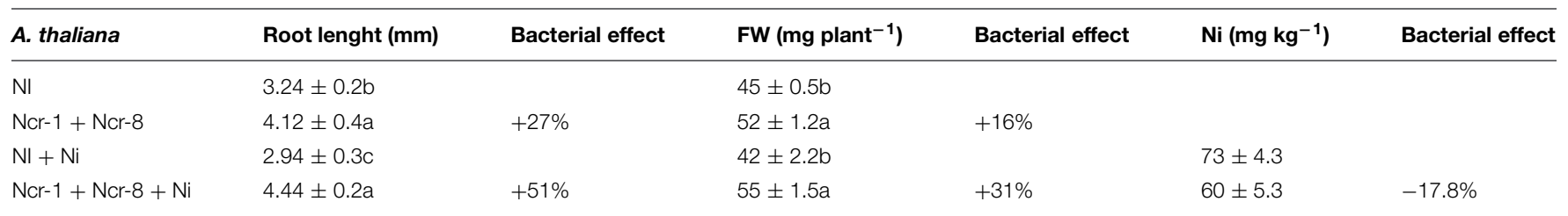

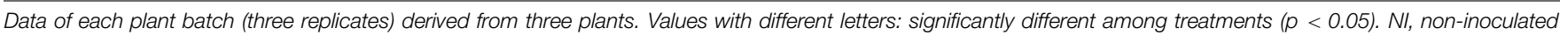
plants; FW, fresh plant weight. 
spaces between epidermal cells and crowding particularly round the stomata complexes. This finding is noteworthy, because epidermal cells are the primary sites of $\mathrm{Ni}$ accumulation in this hyperaccumulator species, although clear exclusion of $\mathrm{Ni}$ from guard cells was also recently reported by Mattarozzi et al. (2015).

\section{Ncr-1 and Ncr-8 Co-Inoculum Enhances Arabidopsis Root Growth and Tolerance to Ni}

The effectiveness of the combination of Ncr-1 and Ncr-8 was also tested in the non-hyperaccumulator A. thaliana. Figure 6 shows non-inoculated vs. Ncr-1 + Ncr-8 co-inoculated 7-dayold seedlings. The treated plants revealed enhanced root and shoot growth both with $(40 \mathrm{mM} \mathrm{NiSO} 4)$ and without $\mathrm{Ni}$ contamination (Table 7). In addition, when the growing medium was contaminated by $\mathrm{Ni}$, the inoculated plants clearly showed fewer symptoms of phytoxicity than controls, with a $50 \%$ increase in root length and an $\sim 30 \%$ increase in plant biomass compared with non-inoculated controls. Although bacteria led to reduced $\mathrm{Ni}$ concentration in plant tissues, the balance of metal removal was still better than that of controls $(p<0.05$; Table 7$)$.

Although the role of PGPR in promoting growth and $\mathrm{Ni}$ uptake in hyperaccumulators has often been reported (Visioli et al., 2015), the protective effect against $\mathrm{Ni}$ toxicity exerted by metal-resistant PGPR or PGPE in non-accumulator biomass species has rarely been documented. For instance, Someya et al. (2007) demonstrated that the Pseudomonas putida ARB86 strain isolated from a Ni-contaminated soil could increase Arabidopsis plant growth and reduce Ni influx. The PGPR Kluyvera ascorbata strain, isolated from a Ni-Cu mining area, protected canola and tomato from $\mathrm{Ni}$ toxicity, mainly by stimulating root growth, but did not hamper $\mathrm{Ni}$ accumulation by the plant (Burd et al., 1998). The positive role played by these bacteria appear to be similar to those of our Ncr-1 and Ncr-8 strains in the presence of $\mathrm{Ni}$, exerting a growth-promoting effect in roots and probably reducing plant stress thanks to reduced ethylene production (see Table 1). In our case, the Ni concentration in Arabidopsis tissues was reduced as a consequence of bacterial inoculation, probably because of metal dilution in a more elevated biomass or reduction in uptake. The absolute difference between inoculated and control plants of $A$. thaliana was minimal when compared with that of $N$. caerulescens, and A. thaliana maintained the characteristics of a non-hyperaccumulator, with a much lower order of magnitude for $\mathrm{Ni}$ accumulation $\left(\mathrm{mg} \mathrm{kg}^{-1}\right.$ vs. $\mathrm{g} \mathrm{kg}^{-1}$ ).

Extensive research is necessary to examine the possible influence of PGPR and PGPE inoculation on changes of speciation of toxic metals in the rhizosphere and to ascertain whether such changes can alter the accumulation and distribution in plant organs of heavy metals in hyperaccumulator and nonhyperaccumulator plants.

\section{References}

Abou-Shanab, R. A., Angle, J. S., and Chaney, R. L. (2006). Bacterial inoculants affecting nickel uptake by Alyssum murale from low, moderate and high Ni soils. Soil Biol. Biochem. 38, 2882-2889. doi: 10.1016/j.soilbio.2006.04.045

\section{Conclusion}

Highly Ni-polluted serpentine soils are populated by a wide range of bacterial species and strains which play an active role in plant adaptations to extreme soil conditions. Culturable root endophytic bacteria represent only the evaluable part of the community of rhizosphere microorganisms, and the involvement of viable but not cultivable (VBNC) bacteria cannot be excluded.

In this paper, we demonstrate that individual PGPE culturable bacteria are ineffective in plant growth and $\mathrm{Ni}$ accumulation enhancement, although they were selected for their high $\mathrm{Ni}$ resistance. Among selected strains, those belonging to the Arthrobacter and Microbacterium genera alone led to better plant performance, but revealed a synergistic effect when associated as seed inocula in N. caerulescens. Very probably, co-inoculation of various PGPE bacteria partially mimicks the natural conditions of serpentine soils, in which multiple microorganism interactions occur, helping plants to cope with the toxic effects of heavy metals. Co-inoculation can also improve the phytoextraction of various metals at the same time, as we found for $\mathrm{Ni}, \mathrm{Co}$, and $\mathrm{Cu}$, which indicates the possibility of exporting the technology to multiple metal contaminated sites. For these purposes, bacterial strain selection is recommended to be based on metal resistance and IAA over productivity, but with particular attention to ACC-deaminase activity, which reduces plant stress, aging and senescence.

Attempts to extend the technology to non-hyperaccumulator plants led to positive results in terms of root and shoot growth in A. thaliana, although with low tissue $\mathrm{Ni}$ concentration, not comparable with the results from $N$. caerulescens. However, our isolates can contribute to the creation of a "phytoremediating bacteria database," to be tested on high biomass-yielding plant species under multiple metal-contaminated sites for phytoextraction purposes.

\section{Funding}

This research was supported by funds to Prof. Anna Maria Sanangelantoni and Dr. Giovanna Visioli from FIL, of the University of Parma Local Funding for Research.

\section{Acknowledgments}

The authors would like to thank the Emilia Romagna region (Italy) SITEIA.PARMA Technopole (POR FESR 2007-2013) (NM), Prof. Maria Careri for allowing access to ESEM facilities, and Prof. Roberto Perris for allowing access to optical microscopy facilities. Gabriel Walton is also thanked for revision of the English text.

Abou-Shanab, R. A., Angle, J. S., Delorme, T. A., Chaney, R. L., van Berkum, P., Moawad, H., et al. (2003). Rhizobacterial effects on nickel extraction from soil and uptake by Alyssum murale. New Phytol. 158, 219-224. doi: 10.1046/j.1469-8137.2003. 00721.x 
Baker, A. J. M., McGrath, S. P., Reeves, R. D., and Smith, J. A. C. (2000). "Metal hyper accumulator plants: a review of the ecology and physiology of a biological resource for phytoremediation of metal-polluted soils," in Phytoremediation of Contaminated Soil and Water, Chap. 5, eds N. Terry and G. Bañuelos (Boca Raton, FL: CRC Press), 85-107.

Bashan, Y., Kamnev, A. A., and de-Bashan, L. E. (2013a). A proposal for isolating and testing phosphate-solubilizing bacteria that enhance plant growth. Biol. Fertil. Soils 49, 1-2. doi: 10.1007/s00374-012-0756-4

Bashan, Y., Kamnev, A. A., and de-Bashan, L. E. (2013b). Tricalcium phosphate is inappropriate as a universal selection factor for isolating and testing phosphatesolubilizing bacteria that enhance plant growth: a proposal for an alternative procedure. Biol. Fertil. Soils 49, 465-479. doi: 10.1007/s00374-012-0737-7

Becerra-Castro, C., Monterroso, C., Prieto-Fernández, Á., Rodríguez-Lamas, L., Loureiro-Viñas, M., Acea, M. J., et al. (2012). Pseudometallophytes colonising $\mathrm{Pb} / \mathrm{Zn}$ mine tailings: a description of the plant-microorganism-rhizosphere soil system and isolation of metal-tolerant bacteria. J. Hazard. Mater. 217-218, 350-359. doi: 10.1016/j.jhazmat.2012.03.039

Belimov, A. A., Dodd, I. C., Hontzeas, N., Theobald, J. C., Safronova, V. I., and Davies, W. J. (2009). Rhizosphere bacteria containing 1-aminocyclopropane1-carboxylate deaminase increase yield of plants grown in drying soil via both local and systemic hormone signalling. New Phytol. 181, 413-423. doi: 10.1111/i.1469-8137.2008.02657.x

Berlyn, C. B., and Miksche, J. P. (1976). Botanical Microtechnique and Cytochemistry. Ames, IA: Iowa State University Press.

Burd, G. I., Dixon, D. G., and Glick, B. R. (1998). A plant growth-promoting bacterium that decreases nickel toxicity in seedlings. Appl. Environ. Microbiol. 64, 3663-3668.

Cabello-Conejo, M., Becerra-Castro, C., Prieto-Fernández, A., Monterroso, C., Saavedra-Ferro, A., Mench, M., et al. (2014). Rhizobacterial inoculants can improve nickel phytoextraction by the hyperaccumulator Alyssum pintodasilvae. Plant Soil 379, 35-50. doi: 10.1007/s11104-014-2043-7

Chaney, R. L., Angle, J. S., Broadhurst, C. L., Peters, C. A., Tappero, R. V., and Sparks, D. L. (2007). Improved understanding of hyperaccumulation yields commercial phytoextraction and phytomining technologies. J. Environ. Qual. 36, 1429-1443. doi: 10.2134/jeq2006.0514

Chen, L., Luo, S. L., Xiao, X., Guo, H. J., Chen, J. L., Wan, Y., et al. (2010). Application of plant growth-promoting endophytes (PGPE) isolated from Solanum nigrum L. for phytoextraction of Cd-polluted soils. Appl. Soil Ecol. 46, 383-389. doi: 10.1016/j.apsoil.2010.10.003

Dell'Amico, E., Cavalca, L., and Andreoni, V. (2008). Improvement of Brassica napus growth under cadmium stress by cadmium-resistant rhizobacteria. Soil Biol. Biochem. 40, 74-84. doi: 10.1016/j.soilbio.2007.06.024

Ebbs, S. D., and Kochian, L. V. (1998). Phytoextraction of zinc by oat (Avena sativa), barley (Hordeum vulgare) and Indian mustard (Brassica juncea). Environ. Sci. Technol. 32, 802-806. doi: 10.1021/es970698p

Glick, B. R., Penrose, D. M., and Li, J. (1998). A model for the lowering of plant ethylene concentrations by plant growth promoting bacteria. J. Theor. Biol. 190, 63-68. doi: 10.1006/jtbi.1997.0532

He, H., Ye, Z., Yang, D., Yan, J., Xiao, L., Zhong, T., et al. (2013). Characterization of endophytic Rahnella sp. JN6 from Polygonum pubescens and its potential in promoting growth and $\mathrm{Cd}, \mathrm{Pb}, \mathrm{Zn}$ uptake by Brassica napus. Chemosphere 90 , 1960-1965. doi: 10.1016/j.chemosphere.2012.10.057

Jiang, C. Y., Sheng, X. F., Qian, M., and Wang, Q. Y. (2008). Isolation and characterization of a heavy metal-resistant Burkholderia sp. from heavy metalcontaminated paddy field soil and its potential in promoting plant growth and heavy metal accumulation in metal-polluted soil. Chemosphere 72, 157-164. doi: 10.1016/j.chemosphere.2008.02.006

Jing, Y. X., Yan, J. L., He, H. D., Yang, D. J., Xiao, L., Zhong, T., et al. (2014). Characterization of bacteria in the rhizosphere soils of Polygonum pubescens and their potential in promoting growth and $\mathrm{Cd}, \mathrm{Pb}, \mathrm{Zn}$ uptake by Brassica napus. Int. J. Phytorem. 16, 321-333. doi: 10.1080/15226514.2013.773283

Kamnev, A. A. (2003). "Phytoremediation of heavy metals: an overview," in Recent Advances in Marine Biotechnology, Vol. 8, "Bioremediation," eds M. Fingerman and R. Nagabhushanam (Enfield, NH: Science Publishers, Inc.), 269-317.

Li, W. C., Ye, Z. H., and Wong, M. H. (2007). Effects of bacteria on enhanced metal uptake of the Cd/Zn-hyperaccumulating plant, Sedum alfredii. J. Exp. Bot. 58, 4173-4182. doi: 10.1093/jxb/erm274

Ma, Y., Prasad, M. N. V., Rajkumar, M., and Freitas, H. (2011a). Plant growth promoting rhizobacteria and endophytes accelerate phytoremediation of metalliferous soils. Biotechnol. Adv. 29, 248-258. doi: 10.1016/j.biotechadv.2010.12.001

Ma, Y., Rajkumar, M., Luo, Y., and Freitas, H. (2011b). Inoculation of endophytic bacteria on host and non-host plants-effects on plant growth and Ni uptake. J. Hazard. Mater. 195, 230-237. doi: 10.1016/j.jhazmat.2011. 08.034

Ma, Y., Rajkumar, M., and Freitas, H. (2009a). Improvement of plant growth and nickel uptake by nickel resistant-plant growth promoting bacteria. J. Hazard. Mater. 166, 1154-1161. doi: 10.1016/j.jhazmat.2008.12.018

Ma, Y., Rajkumar, M., and Freitas, H. (2009b). Isolation and characterization of $\mathrm{Ni}$ mobilizing PGPB from serpentine soils and their potential in promoting plant growth and Ni accumulation by Brassica spp. Chemosphere 75, 719-725. doi: 10.1016/j.chemosphere.2009.01.056

Ma, Y., Rajkumar, M., Rocha, I., Oliveira, R. S., and Freitas, H. (2015a). Serpentine bacteria influence metal translocation and bioconcentration of Brassica juncea and Ricinus communis grown in multi-metal polluted soils. Front. Plant Sci. 5:757. doi: 10.3389/fpls.2014.00757

Ma, Y., Oliveira, R. S., Nai, F., Rajkumar, M., Luo, Y., Rocha, I., et al. (2015b). The hyperaccumulator Sedum plumbizincicola harbors metal-resistant endophytic bacteria that improve its phytoextraction capacity in multi-metal contaminated soil. J. Environ. Manag. 156, 62-69. doi: 10.1016/j.jenvman.2015. 03.024

Mattarozzi, M., Visioli, G., Sanangelantoni, A. M., and Careri, M. (2015). ESEMEDS: in vivo characterization of the Ni hyperaccumulator Noccaea caerulescens. Micron 75, 18-26. doi: 10.1016/j.micron.2015.04.012

Murashige, T., and Skoog, F. (1962). A revised medium for rapid growth and bio-assays with tobacco tissue cultures. Physiol. Plant. 15, 473-497.

Rajkumar, M., Ae, N., and Freitas, H. (2009). Endophytic bacteria and their potential to enhance heavy metal phytoextraction. Chemosphere 77, 153-160. doi: 10.1016/j.chemosphere.2009.06.047

Rajkumar, M., and Freitas, H. (2008). Influence of metal resistant-plant growth promoting bacteria on the growth of Ricinus communis in soil contaminated with heavy metals. Chemosphere 71, 834-842. doi: 10.1016/j.chemosphere.2007.11.038

Rajkumar, M., Sandhya, S., Prasad, M. N. V., and Freitas, H. (2012). Perspectives of plant-associated microbes in heavy metal phytoremediation. Biotechnol. Adv. 30, 1562-1574. doi: 10.1016/j.biotechadv.2012.04.011

Sessitsch, A., Kuffner, M., Kidd, P., Vangronsveld, J., Wenzel, W. W., Fallman, K., et al. (2013). The role of plant-associated bacteria in the mobilization and phytoextraction of trace elements in contaminated soils. Soil Biol. Biochem. 60, 182-194. doi: 10.1016/j.soilbio.2013.01.012

Sheng, X. F., Xia, J. J., Jiang, C. Y., He, L. Y., and Qian, M. (2008). Characterization of heavy metal-resistant endophytic bacteria from rape (Brassica napus) roots and their potential in promoting the growth and lead accumulation of rape. Environ. Pollut. 156, 1164-1170. doi: 10.1016/j.envpol.2008. 04.007

Singh, N. K., Rai, U. N., Verma, D. K., and Rathore, G. (2014). Kocuria flava induced growth and chromium accumulation in Cicer arietinum L. Int. J. Phytorem. 16, 14-28. doi: 10.1080/15226514.2012.723065

Someya, N., Sato, Y., Yamaguchi, I., Hamamoto, H., Ichiman, Y., Akutsu, K., et al. (2007). Alleviation of nickel toxicity in plants by a rhizobacterium strain is not dependent on its siderophore production. Comm. Soil Sci. Plant Anal. 38, 1155-1162. doi: 10.1080/00103620701328040

Spaepen, S., Vanderleyden, J., and Remans, R. (2007). Indole-3-acetic acid in microbial and microorganism-plant signaling. FEMS Microbiol. Rev. 31, 425448. doi: 10.1111/j.1574-6976.2007.00072.x

Stabentheiner, E., Zankel, A., and Pölt, P. (2010). Environmental scanning electron microscopy (ESEM)-a versatile tool in studying plants. Protoplasma 246, 89-99. doi: 10.1007/s00709-010-0155-3

Storer, D. A. (1984). A simple high sample volume ashing procedure for determination of soil organic matter. Comm. Soil Sci. Plant Anal. 15, 759-772. doi: 10.1007/s00709-010-0155-3

USEPA. (1995). "Microwave assisted acid digestion of siliceous and organically based matrices," in Test Methods for Evaluating Solid Waste, 3rd Edn, Method 3052. Washington, DC: US Environmental Protection Agency.

Visioli, G., D'Egidio, S., and Sanangelantoni, A. M. (2015). The bacterial rhizobiome of hyperaccumulators: future perspectives based on omics analysis and advanced microscopy. Front. Plant Sci. 5:752. doi: 10.3389/fpls.2014. 00752 
Visioli, G., D’Egidio, S., Vamerali, T., Mattarozzi, M., and Sanangelantoni, A. M. (2014). Culturable endophytic bacteria enhance Ni translocation in the hyperaccumulator Noccaea caerulescens. Chemosphere 117, 538-544. doi: 10.1016/j.chemosphere.2014.09.014

Visioli, G., Menta, C., Gardi, C., and Conti, F. D. (2013). Metal toxicity and biodiversity in serpentine soils: application of bioassay tests and microarthropod index. Chemosphere 90, 1267-1273. doi: 10.1016/j.chemosphere.2012.09.081

Yuan, M., He, H., Xiao, L., Zhong, T., Liu, H., Li, S., et al. (2014). Enhancement of Cd phytoextraction by two Amaranthus species with endophytic Rahnella sp. JN27. Chemosphere 103, 99-104. doi: 10.1016/j.chemosphere.2013.11.040
Conflict of Interest Statement: The authors declare that the research was conducted in the absence of any commercial or financial relationships that could be construed as a potential conflict of interest.

Copyright ( 2015 Visioli, Vamerali, Mattarozzi, Dramis and Sanangelantoni. This is an open-access article distributed under the terms of the Creative Commons Attribution License (CC BY). The use, distribution or reproduction in other forums is permitted, provided the original author(s) or licensor are credited and that the original publication in this journal is cited, in accordance with accepted academic practice. No use, distribution or reproduction is permitted which does not comply with these terms. 